\title{
Efeitos potencialmente alelopáticos dos óleos essenciais de Piper hispidinervium C. DC. e Pogostemon heyneanus Benth sobre plantas daninhas
}

\author{
Antônio Pedro da Silva SOUZA FILHO ${ }^{1}$, Marcus Arthur Marçal de VASCONCELOS ${ }^{1}$, Maria das Graças \\ Bichara $\mathrm{ZOGHBI}^{2}$, Roberto Lisboa CUNHA ${ }^{1}$
}

\begin{abstract}
RESUMO
Este trabalho teve por objetivo caracterizar a atividade potencialmente alelopática de óleos essenciais de pimenta longa (Piper hispidinervium C. DC.) e oriza (Pogostemon heyneanus Benth) e analisar, comparativamente, seus efeitos alelopáticos. Óleos essenciais obtidos foram preparados em concentraçōes de 0,25, 0,5 e 1,0\%, tendo como eluente o éter metílico, e testados sobre a germinação de sementes, desenvolvimento da radícula e do hipocótilo das plantas daninhas de área de pastagens cultivadas, malícia (Mimosa pudica) e mata-pasto (Senna obtusifolia). Os óleos das duas espécies evidenciaram atividade alelopática em intensidades que variaram em função da concentração do óleo, da espécie doadora, da planta receptora e do fator da planta analisado. A germinação das sementes foi o fator mais intensamente inibido pelos óleos. As intensidades das inibiçôes estiveram positivamente associadas à concentração, com inibições máximas verificadas a 1,0\%. Malícia foi à espécie receptora mais sensível aos efeitos do óleo. Comparativamente, o óleo essencial da pimenta longa revelou maior potencial para inibir a germinação e o desenvolvimento das duas plantas receptoras, notadamente em relação à germinação de sementes, quando as diferenças foram mais marcantes. Os resultados foram atribuídos à composição química dos óleos, especialmente em relação à presença de monoterpenos, monoterpenos oxigenados e sesquiterpenos.
\end{abstract}

PALAVRAS-CHAVE: Alelopatia, Inibição, Monoterpenos, Sesquiterpenos.

\section{Potentially allelopathic effects of the essential oils of Piper hispidinervium C. DC. and Pogostemon heyneanus (Benth) on weeds}

\begin{abstract}
This study aimed to characterize the potential allelopathic activity of essential oils of pimenta longa (Piper hispidinervium C. DC.) and oriza (Pogostemon heyneanus Benth), and to examine, comparatively, their allelopathic effects. Essential oils obtained were prepared at concentrations of $0.25 \%, 0.5 \%$ and $1.0 \%$, with ether methanol as eluent, and tested upon the germination of seeds and the development of the radicle and the hypocotyl of the weeds of cultivated grassland areas, malícia (Mimosa pudica) and mata-pasto (Senna obtusifolia). Depending on their concentrations, oils of the two species showed intensities of allelopathic activity on the donor species, on the receptor plant and on the examined plant factor. The germination of seeds was the factor most strongly inhibited by the oils. The intensities of inhibitions were positively related to the concentration, with the maximum inhibitions verified at $1 \%$. Mimosa pudica was the receptor species most sensitive to the effects of oil. In comparison, the essential oil of Piper hispidinervium showed a higher potential for inhibiting the germination and development of the two receptor plants, notably in relation to the germination of seeds, when the differences were more striking. The results were attributed to the chemical composition of oils, especially in relation to the presence of monoterpenes, oxygenated monoterpenes and sesquiterpenes.
\end{abstract}

KEY WORDS: Allelopathy, Inhibition, Monoterpenes, Sesquiterpenes

\footnotetext{
1 Embrapa Amazônia Oriental, Trav. Dr. Enéas Pinheiro, S/N. Marco, 66095-100 Belém, PA, Brasil. Tel: + 55313204 1017,Fax + 5531 32760323, rlisboa@cpatu.embrapa.br

2 Museu Paraense Emílio Goeldi, Av. Perimetral, 1901. Terra Firme, 66077-830 Belém, PA, Brasil. Tel: + 55313217 6010, Fax: + 5531 3274 9491, zoghbi@museu-goeldi.br
} 


\section{INTRODUÇÃO}

Historicamente, os óleos essências têm desempenhado papel importante para a humanidade. A utilização de espécies de plantas produtoras de óleos essenciais envolve deste a indústria de perfumes, de alimentos, como na medicina popular (Sonwa \& König, 2001). Além disso, foram relatadas informaçôes referentes à possibilidade de utilização de óleo essencial nas atividades agrícolas como alternativa viável com ação inseticida, fumigante e fungicida (Ismar, 2000; Miyazawa et al., 1997; Ngoh et al., 1998; Hoagland, 1999; MontesBelmont \& Carvajal, 1999; Bastos \& Albuquerque, 2004).

Adicionalmente a todas essas possibilidades de uso, os óleos essenciais revelam-se como potentes inibidores da germinação de sementes e do desenvolvimento de diferentes espécies de plantas, ação de bioerbicida (Kwak et al., 1999; Duke et al., 2000; Romagni et al., 2000; Duke et al., 2002).

A floresta Amazônica Brasileira, até pela sua riqueza e diversidade biológica, pode oferecer a oportunidade para descobertas de inovadoras e eficientes moléculas com potencial de uso, em larga escala, na agricultura, tanto para o controle de pragas agrícolas de importância econômica, como, também, no controle de plantas daninhas. Especificamente em relação às plantas Amazônicas produtoras de óleos essências, Maia et al. (2001) listaram 90 espécies de plantas nativas da Amazônia com tal características, evidenciando todo o manancial à disposição para prospecção química.

Pimenta longa (Piper hispidinervium C. DC.) pertencente à família Piperaceae, nativa da Amazônia brasileira, de importância econômica relevante, devido apresentar entre os constituintes químicos de seu óleo essencial, o safrol, muito utilizado, na indústria de perfumaria, como fixador de odor. Enquanto oriza (Pogostemon heyneanus Benth), uma Lamiaceae, seu centro de origem na Índia, é cultivada na Indonésia e Malásia de forma intensiva, já na América do sul a planta é cultivada no Paraguai e Brasil, possui um óleo essencial com odor característico, persistente e canforáceo (Maia et al., 2001).

Este trabalho teve por objetivo caracterizar a atividade potencialmente alelopática dos óleos essenciais de pimenta longa e oriza e analisar, comparativamente, seus efeitos sobre a germinação de sementes e o desenvolvimento de plantas daninhas de área de pastagens cultivadas, tendo em vista um potencial herbicidada no controle de ervas invasoras.

\section{MATERIAL E MÉTODOS}

\section{MATERIAL VEGETATIVO E OBTENÇÃO DOS ÓLEOS ESSENCIAIS}

O trabalho foi desenvolvido na Embrapa Amazônia Oriental, Belém, Pará. Os materiais vegetativos, folhas e galhos de pimenta longa (P. hispidinervium C. DC.) e oriza
(P. heyneanus Benth) foram obtidos junto a produtores da região de Belém, Pará. A biomassa da pimenta longa foi seca ao abrigo do sol, mas com ventilação forçada através de um sistema de circulação do ar, enquanto as folhas e os galhos da oriza foram secos sob proteção do sol e com ventilação natural. Os procedimentos de secagem tiveram a duração de 7 dias. Após a secagem, tanto da pimenta longa quanto da oriza, a biomassa teve as folhas e galhos finos separados. Os materiais assim obtidos foram submetidos, individualmente, aos processos de extração e destilação de óleo essencial, utilizando extrator modelo ASSS-100, série S/14597, com capacidade cúbica para 100 litros de material, marca SHIMIZU Scientific Instruments MFG. Co, Ltd., acoplado a um trocador de calor marca ORION. O período de extração foi de 6 h, não ultrapassando a pressão de $0,2 \mathrm{kgf} / \mathrm{cm}^{2}$, durante toda a extração. A mistura de vapor de água e óleo essencial foi arrastada até o condensador. Por meio de resfriamento ocorreu a mudança de fase e posterior separação da mistura por decantação. A fração de óleo essencial foi recuperada e desidratada em funil de separação com auxílio de $\mathrm{Na}_{2} \mathrm{SO}_{4}$ anidro. Os óleos assim obtidos foram imediatamente armazenados em frasco de cor âmbar até o momento da utilização, em geladeira.

\section{IDENTIFICAÇÃO DOS CONSTITUINTES QUIIMICOS DOS ÓLEOS ESSENCIAIS}

A composição química (\%) dos óleos essenciais foi determinada conforme descrita por Adams (2007), utilizandose Cromatografia de Fase Gasosa acoplada a Espectrometria de Massa (CG/EM). As análises foram realizadas em sistema Shimadzu-QP2010 Plus, equipado com coluna capilar de sílica fundida Rtx-5MS ( $30 \mathrm{~m}$ x 0,25mm; 0,25 mm), operando nas seguintes condiçôes: fluxo de coluna $1,0 \mathrm{~mL} / \mathrm{min}$; tipo de injeção: splitless $(1 \mathrm{~mL}$, razão do split 2:1000), utilizandose hélio como gás de arraste $(54,0 \mathrm{~mL} / \mathrm{min})$; temperatura programada do forno $250^{\circ} \mathrm{C}$. Impacto eletrônico de 70 $\mathrm{eV}$, temperatura da fonte de íons a $200^{\circ} \mathrm{C}$, temperatura de interface de $250^{\circ} \mathrm{C}$. Os componentes foram identificados por comparação dos espectros de massa e índices de retenção com aqueles da biblioteca do sistema. Os dados quantitativos foram obtidos por integração eletrônica da área dos picos.

\section{BIOENSAIOS DE GERMINAÇÃO}

O trabalho foi desenvolvido em câmara de germinação, com temperatura constante de $25^{\circ} \mathrm{C}$ e fotoperiodo de $12 \mathrm{~h}$. A germinação das sementes foi monitorada em períodos de 10 dias, com contagens diárias e eliminação das sementes germinadas. Foi considerada semente germinada aquela que apresentava extensão radicular igual ou superior a 2,00 $\mathrm{mm}$. Cada placa de Petri de $9,0 \mathrm{~cm}$ de diâmetro, forrada com uma folha de papel de filtro qualitativo, recebeu 30 sementes, constituindo-se em uma parcela experimental. 


\section{BIOENSAIOS DE DESENVOLVIMENTO DAS PLANTAS}

Também foram desenvolvidos em câmaras, com temperatura constante de $25^{\circ} \mathrm{C}$ e fotoperiodo de $24 \mathrm{~h}$. Cada placa de Petri de 9,0 cm de diâmetro recebeu três sementes, pré-germinadas, há três dias de germinadas. Ao final do período de 10 dias de crescimento, mediu-se o comprimento da radícula e do hipocótilo.

\section{OUTROS PROCEDIMENTOS EXPERIMENTAIS}

Cada placa de Petri recebeu 3,0 mL da solução teste, forradas com papel filtro esterelizado. Após a evaporação do solvente, éter etílico, foi adicionado um volume equivalente de água destilada, mantendo-se, dessa forma, a concentração original. As soluçóes testes foram adicionadas apenas uma vez, quando do início dos bioensaios, sendo a partir de então, adicionado apenas água destilada, sempre que se fazia necessário. Os óleos essenciais foram testados nas concentrações de 0,25, 0,5 e 1,0\% (v/v).

Como plantas indicadoras dos efeitos potencialmente alelopáticos, utilizaram-se as espécies de plantas daninhas, Mimosa pudica (malícia) e Senna obtusifolia (mata-pasto). As sementes dessas duas espécies foram coletadas em áreas de pastagens cultivadas, no Município de Terra Alta, Estado do Pará, passaram por processo de limpeza e foram tratadas com vista à quebra de dormência, vias imersão em ácido sulfúrico, por $20 \mathrm{~min}$, conforme especificado por Souza Filho et al. (1998).

\section{DELINEAMENTO EXPERIMENTAL E ANÁLISE ESTATÍSTICA}

O delineamento experimental foi do tipo inteiramente casualizado, com quatro repetições, tendo como testemunha a água destilada, em modelo hierárquico, com dois fatores. Os dados foram transformados em arco-seno $\sqrt{x}_{\mathrm{x}}$, para seguirem distribuição normal. Os valores obtidos foram submetidos a análise de variância, teste $\mathrm{F}$, e quando os efeitos de tratamentos apresentaram diferença significativa $(P<0,01)$, as médias foram comparadas por meio do teste de regressão. Para as análises utilizou-se o programa computacional Statistical Analysis System, SAS (SAS, 1989).

\section{RESULTADOS E DISCUSSÃO}

Em estudos de avaliação da atividade fitotóxica de extratos brutos, cuidados especiais devem ser dirigidos para o fator potencial osmótico, mesmo porque alelopatia e potencial osmótico apresentam efeitos aditivos, levando a superestimar os efeitos alelopáticos (Souza Filho, 2006). Neste trabalho, para todas as concentraçôes testadas, inclusive a máxima de $1 \%$, os efeitos osmóticos foram desprezados, tendo em vista, as indicações de Souza Filho \& Alves (2000).

A intensidade dos efeitos potencialmente alelopático variou em função da concentração, da planta doadora do óleo, da planta receptora e do fator da planta receptora analisado. Independentemente da espécie receptora, os efeitos alelopáticos inibitórios do óleo de pimenta-longa foram mais intensos sobre a germinação das sementes, apresentando inibições de magnitude sempre superior a 46\%; atingindo valores máximos de $77 \%$ sobre a germinação das sementes de Mimosa pudica e 65\% sobre a germinação de Senna obtusifolia (Figura 1). Da mesma forma, o desenvolvimento da radícula e do hipocótilo também foram mais intensos, na medida que aumentava a percentagem da inibição da germinação. De fato, os efeitos inibitórios sobre a germinação de sementes (Figura 1), desenvolvimento da radícula (Figura 2) e do hipocótilo (Figura 3) foram significativamente influenciados pelos tratamentos, notadamente para o óleo essencial da $P$. hispidinervium C. DC. Para o óleo essencial de P. heyneanus Benth essa tendência foi observada, porém com menor magnitude de inibição da germinação.

A atividade biológica de um dado aleloquímico depende tanto da concentração como do limite da resposta da espécie afetada. O limite de inibição para uma dada substância não é constante, porém está intimamente relacionada à sensibilidade da espécie receptora, aos processos da planta e às condições ambientais. No presente trabalho, os efeitos inibitórios estiveram positivamente associados à concentração do óleo e às espécies receptoras, tanto quando se analisaram os efeitos sobre a germinação das sementes (Figura 1), quanto o desenvolvimento da radícula (Figura 2) e do hipocótilo (Figura 3) das duas espécies de plantas receptoras. Inibições crescentes foram sempre obtidas com o aumento da concentração $(P<0,001)$. Invariavelmente, as inibições máximas foram sempre observadas na concentração mais elevada (1\%). No mesmo sentido, a espécie malícia tendeu a apresentar maior sensibilidade aos efeitos potencialmente alelopáticos do que mato-pasto, sendo essa observação mais marcante quando se analisaram os efeitos sobre a germinação das sementes e menos marcante para os efeitos sobre o desenvolvimento do hipocótilo.

De acordo com An et al. (1993), é assumido que um dado aleloquímico possui dois atributos, inibitório e estimulatório. Rice (1984) menciona que quando em baixa concentração os efeitos alelopáticos podem não ser inibitório para dada espécie receptora, podendo apresentar efeitos estimulatórios em determinados casos. Os resultados obtidos neste trabalho mostram que mesmo em concentração tão baixa quanto $0,5 \%$, os efeitos foram sempre inibitórios para as duas espécies receptoras, indicando que provavelmente somente em concentração mais baixas do que $0,5 \%$, efeitos estimulatórios podem ser esperados. Naturalmente que a diferença na sensibilidade evidenciada pelas duas espécies aos efeitos dos óleos essenciais pode contribuir para maior ou menor extensão desses efeitos. Malícia, por revelar maior sensibilidade, tenderia 


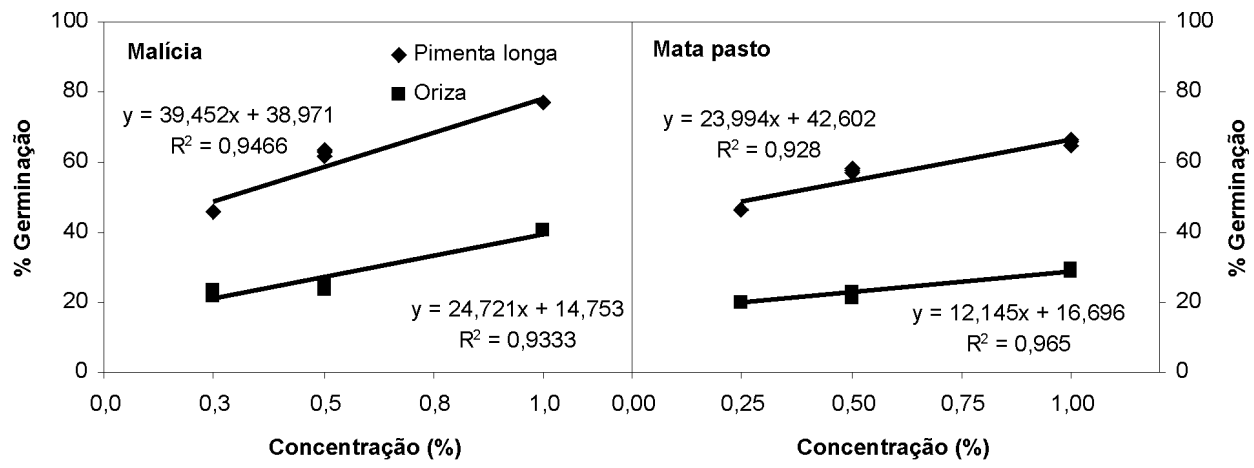

Figura 1 - Efeitos potencialmente alelopáticos de óleos essenciais sobre a germinação de sementes de Malícia e Mata pasto. Dados expressos em percentual de inibição em relação ao tratamento testemunha, água destilada.

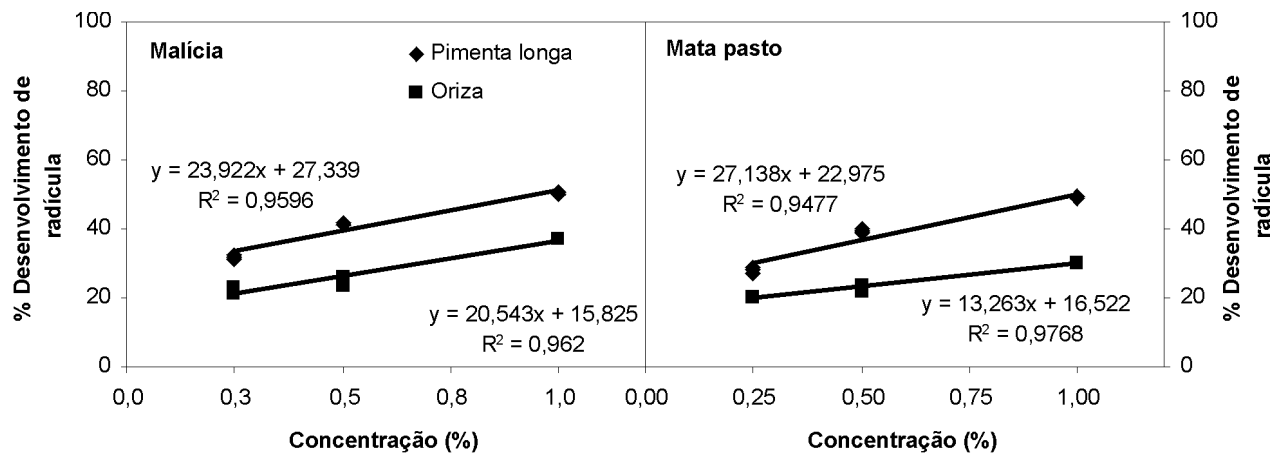

Figura 2 - Efeitos potencialmente alelopáticos de óleos essenciais sobre o desenvolvimento da radícula de sementes de Malícia e Mata pasto. Dados expressos em percentual de inibição em relação ao tratamento testemunha, água destilada.

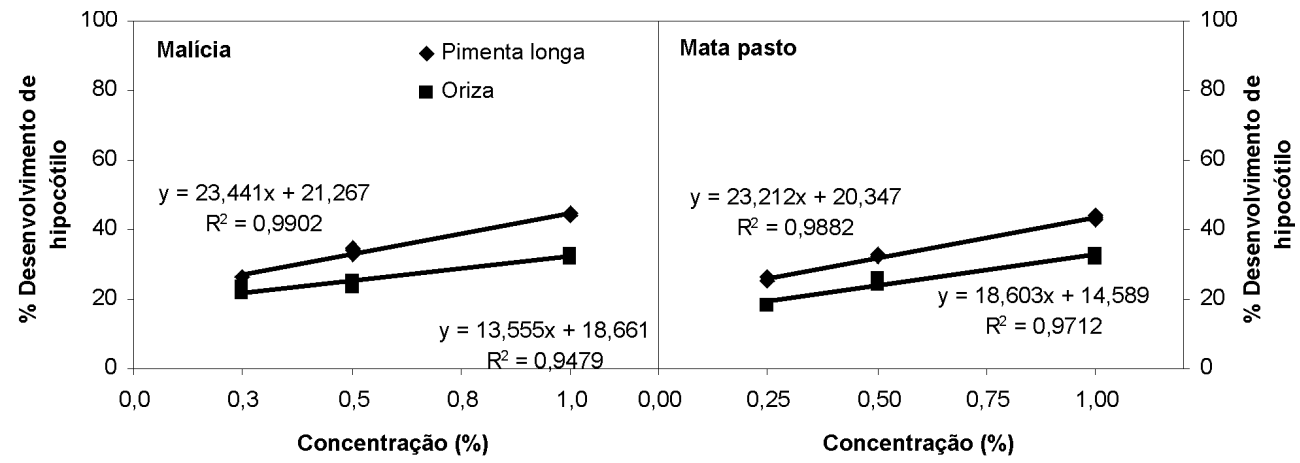

Figura 3 - Efeitos potencialmente alelopáticos de óleos essenciais sobre o desenvolvimento do hipocótilo de sementes de Malícia e Mata pasto. Dados expressos em percentual de inibição em relação ao tratamento testemunha, água destilada. 
a evidenciar efeitos inibitórios em concentrações mais baixas do que mata-pasto, sendo tal diferença mais marcante para a germinação de sementes.

Os efeitos do óleo essencial sobre a germinação de sementes e o desenvolvimento de plantas são freqüentemente explicados em termos individuais de alguns dos principais constituintes. Entretanto, o óleo essencial é uma mistura de diferentes componentes, em proporçôes variadas e é, freqüentemente, desconhecido como esses constituintes interagem entre si e promovem seus efeitos sobre outros organismos. Adicionalmente, há considerável variação na composição do óleo essencial de certas espécies de plantas; tal variação pode ser em função da sazonalidade, da diferença entre indivíduos de populaçōes e indivíduos de mesma população (Tarayre et al., 1995; Kokkini \& Vokou, 1989). Os resultados obtidos no presente trabalho indicaram que independentemente da concentração, da espécie receptora e do parâmetro da planta estudado, pimenta longa evidenciou maior atividade alelopática inibitória da germinação das sementes (Figura 1), e do desenvolvimento da radícula (Figura 2) e do hipocótilo (Figura 3). Essa superioridade pode ser atribuída tanto às diferenças na composição dos constituintes do óleo essencial de cada espécie, como também, à concentração com que cada constituinte é encontrado em cada óleo (Tabela 1).

Na tabela 1 e 2 são apresentados os constituintes dos óleos essenciais de $P$. heyneanus Benth em que foram identificados 15 constituintes, sendo os compostos majoritários o álcool de patchuli $(21,9 \%), \alpha$-bulneseno (11,8\%), $\alpha$-guaieno $(8,6 \%)$, seicheleno $(6,6 \%)$ e $\alpha$-patchuleno $(6,3 \%)$. Ao passo que, em P. hispidinervium $\mathrm{C}$. DC, foram identificaram 21 constituintes sendo os majoritários o safrol $(64,3 \%)$, terpinoleno $(10,2 \%)$, (E)- $\beta$-ocimeno $(5,6 \%), \delta$-3-careno $(3,4 \%)$ e pentadecano $(3,1 \%)$.

Vilhena (2006), por exemplo, comparou duas espécies de Cyperus, e atribuiu as diferenças na intensidade alelopática às diferenças verificadas na composição química dos óleos. Komai et al. (1991) indicou que os óleos essenciais que apresentavam maiores índices de inibição alelopática eram constituídos

Tabela 1 - Análise comparativa da composição química (\%) dos Componentes dos óleos essenciais das duas espécies.

\begin{tabular}{|c|c|c|c|}
\hline Componente (\%) -CG/EM & IR & Pogostemon heyneanus Benth & Piper hispidinervium C. DC \\
\hline$\alpha$-tujeno & 931 & - & 2,7 \\
\hline Mirceno & 994 & - & 1,0 \\
\hline$\alpha$-felandreno & 1009 & - & 0,1 \\
\hline$\delta$-3-careno & 1015 & - & 3,4 \\
\hline p-cimeno & 1027 & - & 1,1 \\
\hline (Z)- $\beta$-ocimeno & 1038 & - & 1,8 \\
\hline (E)- $\beta$-ocimeno & 1049 & - & c \\
\hline Terpinoleno & 1092 & - & 10,2 \\
\hline allo-ocimeno & 1131 & - & 1,1 \\
\hline$p$-cimen-8-ol & 1187 & - & 2,0 \\
\hline Safrol & 1296 & - & 64,3 \\
\hline$\delta$-elemeno & 1340 & 0,1 & 0,3 \\
\hline$\alpha$-copaeno & 1379 & - & 0,2 \\
\hline$\beta$-patchuleno & 1386 & 2,3 & - \\
\hline$\beta$-elemeno & 1396 & 1,6 & 0,1 \\
\hline Metileugenol & 1408 & - & 0,1 \\
\hline Cicloseicheleno & 1414 & 1,0 & - \\
\hline$\beta$-cariofileno & 1424 & 3,1 & 1,0 \\
\hline$\alpha$-guaieno & 1444 & 8,6 & - \\
\hline Seicheleno & 1448 & 6,6 & - \\
\hline$\alpha$-humuleno & 1458 & - & 0,1 \\
\hline$\alpha$-patchuleno & 1462 & 6,3 & - \\
\hline Germacreno-D & 1486 & - & 0,1 \\
\hline Pentadecano & 1500 & - & 3,1 \\
\hline Acilfileno & 1504 & 4,1 & - \\
\hline$\alpha$-bulneseno & 1413 & 11,8 & - \\
\hline 7-epi- $\alpha$-selineno & 1522 & 0,4 & - \\
\hline$\delta$-cadineno & 1526 & - & 0,1 \\
\hline
\end{tabular}




\begin{tabular}{lccc}
\hline Tabela 1 - Continuação & & & \\
\hline Componente (\%) -CG/EM & IR & Pogostemon heyneanus Benth & Piper hispidinervium C. DC \\
\hline nor-patchulenol & 1561 & 1,0 & - \\
Espatulenol & 1579 & - & 0,8 \\
Óxido de cariofileno & 1579 & 1,6 & - \\
Pogostol & 1656 & 0,4 & - \\
Álcool de patchuli & 1671 & 21,9 & - \\
\hline
\end{tabular}

$\mathrm{IR}=$ Índice de retenção

Tabela 2 - Componentes majoritários de os óleos essenciais de Pogostemon heyneanus Benth e Piper hispidinervium C. DC.

\begin{tabular}{lcc}
\hline Componente & \multicolumn{2}{c}{ Teor (\%) } \\
& $\begin{array}{c}\text { Pogostemon heyneanus } \\
\text { Benth }\end{array}$ & $\begin{array}{c}\text { Piper hispidinervium } \\
\text { C. DC }\end{array}$ \\
\hline Álcool de patchuli & 21,9 & - \\
$\alpha$-bulneseno & 11,8 & - \\
$\alpha$-guaieno & 8,6 & - \\
Seicheleno & 6,6 & - \\
$\alpha$-patchuleno & 6,3 & - \\
Safrol & - & 64,3 \\
Terpinoleno & - & 10,2 \\
(E)- $\beta$-ocimeno & - & 5,6 \\
$\delta$-3-careno & - & 3,4 \\
entadecano & - & 3,1 \\
\hline
\end{tabular}

principalmente por sesquiterpenos que continham o grupo cetona ou hidroxila; os óleos constituídos de grupo acetato ou somente hidrocarboneto apresentaram menos atividade alelopática. Entre os constituintes dos óleos das espécies pimenta longa e oriza foram identificados, basicamente, monoterpenos, monoterpenos oxigenados, sesquiterpenos, alifáticos e arilpropanóides. Monoterpenos e monoterpenos oxigenados foram encontrados apenas fazendo parte do óleo essencial da pimenta longa (Tabela 1), que apresentou maior atividade alelopática.

Especificamente em relação àqueles componentes de óleo essencial com atividade alelopática já comprovada e que podem estar envolvidos nos efeitos observados, isoladamente ou em associação com outros componentes, merece destaque o p-cimeno, cuja atividade alelopática inibitória da germinação foi mencionada por Macias et al. (1999). Esse componente está presente no óleo essencial da pimenta longa, porém não no da oriza. Aparentemente, a atividade alelopática dos óleos essenciais das duas espécies pode estar relacionada à presença de monoterpenos, monoterpenos oxigenados e sesquiterpenos.
Como um todo estes resultados sugerem que a utilização de óleos essências apresentou ação inibitória sobre a germinação, o desenvolvimento da radícula e do hipocótilo. As evidências aqui apresentadas indicam efeito mais acentuado quando se utiliza como fonte doadora de óleo essencial à pimenta longa.

\section{BIBLIOGRAFIA CITADA}

Adams, R.P. 2007. Identification of essential oil components by gas chromatography/mass spectrometry. London: Allured Pub. Corp. 804pp.

An, M.; Johnson, I.R.; Lovette, J.V. 1993. Mathematical modeling of allelopathy: biological response to allelochemical and its interpretation. Journal of Chemical Ecology, 19(10): 23792389.

Bastos, C.N.; Albuguerque, P.S.B. 2004. Efeitos do óleo de Piper aduncum no controle e pós-colheita de Colletrotricum musae em banana. Fitopatologia brasileira, 29(5): 555-557.

Dias, A.P.C.; Souza Filho, A.P.S. 2005. Atividade potencialmente alelopática em extratos hidroalcóolicos de Cymbopogon sp. (Poaceae). Revista Ciências Agrárias, 44(1): 37-48.

Duke, S.O.; Dayan, F.E.; Rimando, A.M.; Schirader, K.K.; Aliotta, G.; Oliva, A.; Romagni, J.G. 2002. Chemical from nature for weed management. Weed Science. 50(2): 138-151.

Duke, S.O.; Romagni, J.G.; Dayan, F.E. 2000. Natural products as source from new mechanisms of herbicidal action. Crop Products, 19(8): 583-589.

Hoagland, R.E. 1999. Allelopathic interaction of plant and pathogens. In: Macias, F.A.;

Isman, M.B. 2000. Plant essential oil for pest and disease management. Crop Protection, 19(8): 603-608.

Kokkini, S.; Vokou, D. 1989. Mentha spicata (Lamiaceae) chemotypes growing wild in Greece. Economic Botany, 43(2): 192-202.

Komai, K.; Tang, C.S.; Nishimoto, R.K. 1991. Chemotypes of Cyperus rotundus in Pacific Rim and inhibitory of their essential oils. Journal Chemical Ecology, 17(1): 1-11.

KWAK, S.H.; Kil, B.S.; Soh, W.Y. 1999. Allelopathy effects of Chamaecyparis obtuse in 
Macias, F.A.; Molinillo, J.M.G.; Torres, R.M.V.; Galindo, J.C.G. 1999. Bioactive compounds from the Genus Halianthus. In: Macias, F.A.; Galindo, J.C.G.; Molinillo, J.M.G.; Cutler, H.G. (Eds). Recent advances in allelophaty. Cádiz: International Allelopathy Society, p. 121-148.

Maia, J.G.S.; Zoghbi, M.G.B.; Andrade, E.H.A. 2001. Plantas aromáticas da Amazônia e seus óleos essenciais. Belém: Museu Paraense Emílio Goeldi. 173pp.

Miyazawa, M.; Watanabe, H.; Kameoka, H. 1997. Inhibition of acetylcholinesterase activity by monoterpenoids with a p-methane skeleton. Journal of Agriculture Food Chemical, 45(3): 677-679.

Montes-Belmont, R.; Carvajal, M. 1999. Aspergillus flavus control in maize with plant essential oil. In: Macias, F.A.; Galindo, J.C.G.; Molinillo, J.M.G.; Cutler, H.G. (Eds). Recent advances in allelophaty. Cádiz: International Allelopathy Society, p. 463470.

Ngoh, S.P.; Choo L.E.W.; Pang F.Y.; Yan Huang; Kini M.R.; Ho S.H. 1998. Insecticidal and repellent properties of nine volatile constituents of essential oils against the American cockroach (Periplaneta Americana L.). Pesticide Science, 54(3): 261-268.

Paracampo, N.E.N. 2002. Estudo químico e avaliação da atividade fitotóxica e fungitóxica de extratos de Vouacapoua cf. americana. Dissertação (Mestrado) - Universidade Federal do Pará, Belém, PA. 63p.

Rice, E.L. 1984. Allelopathy. New York: Academic Press, USA. 422pp.
Romagni, J.G.; Duke, S.O.; Dayan, F.E. 2000. Inhibition of plant asparagine synthetase by monoterpene cineol. Plant Physiology, 123(2): 725-732.

SAS. 1989. Statistical Analyses System. Version 6.4. North Caroline. 846pp.

Sonowa, M.M.; König, W.A. 2001. Constituents of the essential oil of Cyperus alopecuroides. Phytochemistry, 56(4): 321-325.

Souza Filho, A.P.S. 2006. Alelopatia e as plantas. Belém: Embrapa. $159 \mathrm{pp}$.

Souza Filho, A.P.S.; Alves, S.M. 2000. Potencial alelopático de plantas de acapu (Vouacapoua americana): efeitos sobre plantas daninhas de pastagens. Planta Daninha, 18(3): 435-441.

Souza Filho, A.P.S.; Dutra, S.; Silva, M.A.M.M. 1998. Métodos de superação da dormência de sementes de plantas daninhas de pastagens cultivadas da Amazônia. Planta Daninha, 16(1): 2-11.

Tarayre, M.; Thompson, J.D.; Escarre, J.; Linhart, Y.B. 1995. Intraspecific variation in the inhibitory effects of Thymus vulgaris (Labiatae) monoterpenes on seed germination. Oecologia, 101 (1): 110-118.

Vilhena, K.S.S. 2006. Estudo químico e atividade alelopática dos extratos brutos e do óleo essencial dos rizomas de Cyperus articulatum L. e Cyperus giganteus Vahl. (Cyperaceae). Dissertação (Mestrado) - Universidade Federal do Pará. 130p.

Recebido em 19/08/2008

Aceito em 17/11/2008 
